\title{
ГОЛОСА МОЛОДЫХ
}

\section{EC: правовое регулирование воздушных сообщений}

Врбашки Лазар

Либерализацией авиационного рынка Европейского союза была положена основа современного правового регулирования воздушных сообщений в ЕС. Регламент № 1008/2008 консолидировал положения о лицензировании авиаперевозчиков ЕС, об их доступе на внутренние воздушные линии Европейского союза и о тарифах на воздушные сообщения с целью повышения эффективности и устойчивости применяемого права ЕС, в попытке выведения внутреннего авиационного рынка $\mathrm{EC}$ на качественно более высокий уровень развития. Посредством сравнительного анализа основных положений нового Регламента и ранее действовавших актов, практических и научных вопросов, возникающих при их применении в региональном и глобальном масштабе, в статье рассматривается совершенствование правового регулирования воздушных сообщений в целях лучшего осмысления достижений ЕС в данной области.

Ключевые слова: Регламент № 1008/2008; лицензирование; доступ на внутренние воздушные линии; общественно значимые перевозки; тарифы.

Начало всестороннего формирования внутреннего авиационного рынка ЕС в его современном виде связывается с принятием третьего пакета правовых актов ЕС, которым завершался процесс либерализации воздушного транспорта в ЕС. В ходе этого процесса наблюдалась

* Врбашки Лазар - аспирант кафедры европейского права МГИМО (У) МИД России. kafedra-ide@mgimo.ru. 
и смена форм правового регулирования. Изначально принимаемые директивы, направленные на гармонизацию законодательства государств - членов ЕС уступили впоследствии свое место регламентам, предпочтительным инструментам унификации правового регулирования ${ }^{1}$. Указанное лишний раз свидетельствует о том, что, как отмечает профессор Г.П. Толстопятенко, «дифференцированный подход к актам Сообществ, видимо, не случаен и обусловлен особенностями их функционального назначения»².

Столь масштабные смены механизмов регулирования авиатранспортной отрасли в региональном масштабе привлекли внимание международного сообщества к проблеме сдерживающего влияния традиционных механизмов регулирования воздушного транспорта на его развитие ${ }^{3}$. В результате необходимость в глобальной либерализации регулирования воздушных сообщений была сначала отмечена на Всемирной авиатранспортной конференции, проведенной в Монреале в 1994 г., а потом стала и предметом Всемирной авиатранспортной конференции 2003 г. на тему «Проблемы и возможности либерализации», организованной ИКАО.

Как отмечает Н.Н. Остроумов, «воздушный пассажирский транспорт является наиболее важным для международного сообщения и динамично развивающимся видом транспорта, а правовое регулирование воздушных перевозок в последние годы обновлено» ${ }^{4}$ В рамках Европейского союза такое обновление проявилось в принятии в 2008 г. ныне действующего Регламента № 1008/2008 об общих правилах осуществления воздушных сообщений в Сообществе (новый Регламент) ${ }^{5}$, который заменил собой три Регламента, регулировавших в совокупности те же вопросы с начала $90-$ х годов ${ }^{6}$.

1 См.: Европейское право. Право Европейского союза и правовое обеспечение защиты прав человека: Учебник / рук. авт. кол. и отв. ред. Л.М. Энтин.2-е изд., пересмотр. и доп. М.: Норма, 2008. С. 107-108.

2 Толстопятенко Г.П. Европейское налоговое право. Сравнительно-правовое исследование. М.: Издательство НОРМА, 2001. С. 37.

3 Бордунов В.Д. Международное воздушное право: Учебное пособие. М.: НОУ ВКШ «Авиабизнес»; изд-во «Научная книга», 2006. С. 77.

${ }^{4}$ Остроумов Н.Н. Договор перевозки в международном воздушном сообщении. М.: Статут, 2009. С. 8.

5 Regulation (EC) No. 1008/2008 of the European Parliament and of the Council of 24 September 2008 on common rules for the operation of air services in the Community. OJ L 293. 31.10.2008. P. 3-20.

${ }^{6}$ Council Regulation (EEC) No. 2407/92 of 23 July 1992 on licensing of air carriers. OJ L 240. 24.8.1992. P. 1-7; Council Regulation (EEC) No. 2408/92 of 23 July 1992 on access 
Вместе с тем стоит отметить, что качественная проработка ряда положений трех указанных регламентов привела к их включению в ныне действующий Регламент № 1008/2008, который и структурирован таким образом, что каждая из регулируемых ранее отдельным регламентом областей занимает в новом Регламенте отдельный раздел. Соответственно, имеет смысл сравнить положения указанных актов, оценивая достижения ЕС в модернизации регулирования воздушных сообщений на внутреннем рынке.

Представляется важным отметить, что вопросы лицензирования авиаперевозчиков в праве ЕС занимают первый раздел Регламента № 1008/2008, что соответствует их роли в правовом регулировании всех остальных аспектов деятельности внутреннего авиатранспортного рынка ЕС. Ибо только лицензированные авиаперевозчики ЕС вправе перевозить пассажиров, почту или груз по территории Союза за вознаграждение ${ }^{8}$. Однако особое значение данной административноправовой меры в праве ЕС заключается не только в этом. Посредством данного процесса формируется особый перечень авиакомпаний, обладающих более широкими правами на внутреннем авиационном рынке, чем авиакомпании третьих стран.

Самый большой по объему раздел нового Регламента посвящен вопросам доступа лицензированных авиаперевозчиков ЕС на внутренние воздушные линии Европейского союза. Регламент № 2408/92 впервые наложил обязанность на государства-члены разрешать авиаперевозчикам ЕС пользоваться коммерческими правами на любых линиях ЕС 9 .

Такая общая формулировка, нашедшая свое место и в новом Регламенте, не могла не поднять вопрос каботажных перевозок, т.е. осуществления авиаперевозчиком одного государства - члена ЕС воздушных перевозок между двумя пунктами, оба из которых находятся

for Community air carriers to intra-Community air routes. OJ L 240. 24.08.1992. P. 8-14; Council Regulation (EEC) No. 2409/92 of 23 July 1992 on fares and rates for air services. OJ L 240. 24/08/1992. P. 15-17.

${ }^{7}$ Претендовать на получение лицензии могут только перевозчики ЕС, головной офис которых (или зарегистрированный офис в котором осуществляются основные финансовые операции и контроль над предприятием, включая поддержку летной годности флота) находится в государстве-члене ЕС, у которого запрашивается лицензия и удовлетворяющие определенные экономические и технические требования.

${ }^{8}$ Данное требование не распространяется на ультралегкие воздушные суда и воздушные суда без двигателей, а также местные полеты, если только правом ЕС, международным правом либо национальным правом не установлено иное.

${ }^{9}$ Регламент № 2408/92. Ст. 3. 
на территории другого государства - члена ЕС. Хотя такие перевозки в международном воздушном праве напрямую не запрещаются, ст. 7 Конвенции о международной гражданской авиации (Чикагской конвенции) не воспрещает государствам-участникам это сделать и в некотором смысле поощряет такой запрет. Дело в том, что основным условием предоставления права осуществления каботажных перевозок является его предоставление всем желающим на неисключительной основе, что, естественно, невыгодно для национальных перевозчиков страны, предоставляющей каботажные права.

Оценивая соответствие рассматриваемого положения регламентов ЕС международному праву, одни авторы, среди которых У.М. Шихан, Д. Гоедхуис, Л. Льюис и др. ${ }^{10}$, не находят такого соответствия. Согласно другой точке зрения, «расширительное толкование «каботажа» способно создать преграду свободной авиации» ${ }^{11}$. Сторонники последней позиции считают, что вторая часть статьи 7 Чикагской конвенции «не запрещает отдельные акты предоставления каботажных прав, при условии, что такое соглашение не упоминает, эксплицитно или имплицитно, что каботажные права были предоставлены на исключительной основе» ${ }^{12}$.

Нельзя не согласиться с мнением авторов, указывающих, что соответствие положений Регламента статье 7 Чикагской конвенции будет зависеть от ответа ЕС на первый поступивший запрос о предоставлении каботажных прав государством, не являющимся членом Союза ${ }^{13}$.

Представляется важным отметить, что с 1944 г. общественные отношения на международном рынке авиаперевозок сильно изменились, в связи с чем вопрос о целесообразности пересмотра или даже исключения статьи 7 Чикагской конвенции все чаще поднимается в научных кругах, как отечественных, так и иностранных ${ }^{14}$. Весьма логично ожидать активное влияние права ЕС в ходе такого пересмотра. Так, для при-

${ }^{10}$ Cм.: I.H.Ph. Diederiks-Verschoor, M.A. Butler. An Introduction to Air Law. Kluwer Law International. 2006. P. 24.

${ }^{11}$ Ibidem.

${ }^{12}$ Mendes de Leon. P. Cabotage in Air Transport Regulation. Martinus Nijhoff Publishers. 1992. P. 65.

${ }_{13}$ См.: Баталов А.А. Проблемы современного международно-правового регулирования воздушных сообщений. Дис. .... канд. юрид. наук. М., 2003. С. 99.

${ }^{14}$ См.: Ю.Н. Малеев. Воздушное пространство: основные конфликтные позиции государств // Пространство и время в мировой политике и международных отношениях: материалы 4 Конвента РАМИ. В 10 т. / Под ред. А.Ю. Мельвиля; Рос. ассоциация междунар. исследований. М.: МГИМО-Университет, 2007. Т. 5. С. 123. 
дания правовой стабильности инициативе ЕС профессор Л. Вебер предлагает убрать второе предложение ст. 7, оставив первое неизменным, обосновывая это тем, что «второе предложение не содержит правила, существенного для сегодняшней системы воздушного транспорта» ${ }^{15}$.

Для правильного понимания особого режима доступа авиаперевозчиков ЕС на внутренние воздушные линии Союза представляется важным остановиться на законодательно установленных ограничениях рассмотренной свободы доступа, возникающих в ходе ежедневного осуществления воздушных перевозок, поскольку именно они позволяют Союзу найти баланс между подчас не совпадающими интересами разных участников внутреннего авиационного рынка.

Ключевым ограничением свободы доступа выступают случаи введения на определенной воздушной линии обязательств по осуществлению общественно значимых перевозок ${ }^{16}$. Представляется, что при нормотворчестве в данной области крайне важно обеспечить превентивный контроль, пресекающий возможные злоупотребления, поскольку при введении указанных обязательств ищется баланс между удовлетворением нужд регионов и соблюдением таких основополагающих начал европейской интеграции, как свобода конкуренции. Такую контрольную роль призван играть критерий наличия минимального обслуживания региона, который является одним из ключевых условий введения обязательств.

Если, согласно Регламенту № 2408/92, таким критерием выступало обслуживание маршрута иными транспортными средствами, способными обеспечить адекватное и бесперебойное сообеение при пассажиропотоке, превышающем 30000 мест в год ${ }^{17}$, то Регламент № 1008/2008 в качестве критерия выдвигает наличие иных видов транспортных средств на маршруте, обеспечивающих бесперебойное сообщение с частотой не менее двух раз в день ${ }^{18}$.

Главный недостаток первой формулировки состоит в том, что ею не устанавливаются параметры бесперебойного сообщения, а сама цифра пассажиропотока мало говорит о потребностях конкретного

${ }^{15}$ L. Weber. EEC transport liberalization and the Chicago Convention. // Annals of Air and Space Law. Vol. XVII-I. 1992. P. 255.

${ }^{16}$ Такие обязательства вводятся на маршрутах, соединяющих ЕС с отдаленными районами Союза, слабо обеспеченными адекватным транспортным сообщением, жизненно важным для экономического и социального развития этих регионов.

${ }^{17}$ Регламент № 2408/92. П. 3 ст. 4.

${ }^{18}$ Регламент № 1008/2008. П. 2 ст. 16. 
региона. Для целого ряда малонаселенных регионов, например, большее значение имеет частота сообщения, нежели пассажиропоток ${ }^{19}$. Однако представляется, что формулировка, содержащаяся в новом Регламенте, также оставляет место для дальнейшего совершенствования, ибо высокая частота сообщений недостаточно информативна при отсутствии указания минимального времени в пути, занимаемого теми видами транспортных средств, которые обслуживают регион. Не следует забывать, что целый ряд затронутых регионов - острова, нуждающиеся не только в надежной связи с материком, обеспечиваемой морским судоходством, но и в более быстрых средствах транспорта, крайне необходимых для оказания скорой помощи, доставки скоропортящихся грузов и неотложной корреспонденции.

Вышеизложенное наглядно демонстрирует, что на внутреннем авиатранспортном рынке ЕС сосуществуют различные нужды регионов - в частоте, скорости и пассажиропотоке транспортного сообщения. Соответственно представляется, что оптимальный критерий введения обязательств, помимо сведений о частоте уже существующих сообщений, должен также включать указания на минимальное время в пути, занимаемое ими при доставке пассажиров и грузов до первых населенных пунктов, не считаемых малообеспеченными необходимым сообщением, а также на минимально допустимое соотношение пассажиропотока и населения такого сообщения.

Немало нового Регламент № 1008/2008 внес и в регулирование тарифов на авиаперевозки, которым также посвящен отдельный раздел нового Регламента, начинающийся с провозглашения того, что авиаперевозчики ЕС и третьих стран на взаимной основе пользуются свободой установления тарифов и ставок на авиасообщение внутри Союза ${ }^{20}$.

Указанное положение наглядно демонстрирует высокий уровень либерализации внутреннего воздушного рынка ЕС, уже в гораздо меньшей степени нуждающегося в протекционизме Европейского союза. Далее новым Регламентом запрещается государствам - членам ЕС принимать меры, дискриминирующие авиаперевозчиков на основе

19 Так, удовлетворяющим требования старого Регламента может быть признано железнодорожное сообщение с необходимым ежегодным пассажиропотоком, которое, однако, связывает отдаленный регион с центральными районами лишь раз в неделю, что явно не представляется адекватным для развития региона, но такую характеристику уже может дать только Суд ЕС по итогам рассмотрения дела, поскольку Регламент не уточняет, что следует считать адекватным.

20 Регламент № 1008/2008. Ст. 22. 
национальности при установлении тарифов и ставок на авиасообщения с третьими странами. Представляется, что такая формулировка появилась под влиянием двусторонних соглашений о воздушных сообщениях.

В русле «политики дерегулирования» США заключили соответствующие договоры, положения которых сильно отличались друг от друга, со многими государствами, в том числе и с государствами - членами $\mathrm{EC}^{21}$. Естественно, это не могло не противоречить основополагающим началам европейской интеграции, не допускающим дискриминацию на основе национальности, что и постановил Суд ЕС в своих решениях от 5 ноября 2002 года ${ }^{22}$. Указанные решения ознаменовали начало масштабной работы по пересмотру и приведению указанных двусторонних соглашений в соответствие с правом ЕС.

Новеллой Регламента № 1008/2008 являются положения о транспарентности ценообразования, нацеленные на укрепление правовой защищенности потребителей на авиатранспортном рынке ЕС. Так, информация о тарифах на авиаперевозку должна включать в себя информацию об авиационном тарифе (ставке); налогах; аэропортовых сборах; других сборах и прочих надбавках (например, топливных сборах $)^{23}$, которые предвидимы и неминуемы на момент публикации информации о тарифе.

Как отмечается в публикациях, немного снижает прогрессивность положений о тарифах на авиасообщения определенная непоследовательность нового Регламента в установлении сферы действия этих норм. К примеру, п. 2 ст. 23 Регламента № 1008/2008 устанавливает, что положения о транспарентности ценообразования распространяются на воздушные сообщения, начинающиеся в аэропорту государства члена ЕС, в то время как согласно ст. 1 Регламента его нормы регулируют вопросы тарифов на внутренних авиалиниях $\mathrm{EC}^{24}$.

${ }^{21}$ Международное право: Учебник / Отв. ред. Ю.М. Колосов, Э.С. Кривчикова. 2-е изд., перераб. и доп. М.: Междунар. отношения, 2005. С. 636.

${ }^{22}$ Cases C-466/98, C-467/98, C-468/98, C-469/98, C-471/98, C-472/98, C-475/98, C-476/98. OJ C 323. 21.12.2002. P. 1-8.

${ }^{23}$ Регламент № 1008/2008. П.1 ст. 23.

${ }^{24} \mathrm{~J}$. Balfour. EC Regulation 1008/2008 on common rules for the operation of air services in the EC - The third package revisited. // Beaumont Bulletin. January 2009. Р. 4. Официальный сайт международной юридической фирмы Clyde \& Co. Систем. требования: Adobe Acrobat Reader. URL: http://www.clydeco.com/attachments/published/3460/Beaumont\%20 Bulletin\%202009_pdf.log.pdf. P. 4. 
В данном отношении нельзя не согласиться с Дж. Бальфуром, полагающим, что формулировка ст. 23 затрагивает вопрос об экстерриториальном применении права ЕС, поскольку ею делается попытка регулирования продажи авиабилетов авиаперевозчиков из третьих стран в этих странах ${ }^{25}$.

В заключение хотелось бы отметить, что Регламентом № 1008/2008 были весьма тщательно и во многом успешно модернизированы положения каждого из трех ранее действовавших регламентов в сфере воздушных сообщений.

Безусловным достижением нового Регламента является сочетание рационального подхода к процессу лицензирования, при котором ведущая роль отводится наиболее опытным в этой области национальным органам. Крайне детально изложены также требования для получения лицензии, должным образом обеспечивающие как защиту от произвола национальных органов, так и достижение главной цели нового Регламента - обеспечение более ясного, эффективного и устойчивого применения права ЕС на внутреннем авиационном рынке.

С повышением необходимости в налаженной системе общественно значимых перевозок их регулирование заняло весьма важное место в новом Регламенте, что отвечает современным общественным отношениям в сфере воздушного транспорта. Вместе с тем недостаточное совершенствование вопросов о критериях, при которых вводятся обязательства по осуществлению общественно значимых перевозок, не укладывается в общую картину прогрессивности Регламента № 1008/2008. При этом указанные вопросы представляются существенными ввиду их определяющего значения в повышении устойчивости и транспарентности правовых актов на авиационном рынке ЕС, что в свою очередь призвано охранять свободу доступа авиаперевозчиков ЕС на внутренние воздушные линии Союза и предотвращать ее злоупотребления.

В сфере тарифов на авиаперевозки акцент законодателя в новом Регламенте сместился из сферы защиты конкуренции в область обеспечения прав потребителей, что нашло отражение в более детальной проработке статей, обеспечивающих ясность, недвусмысленность и транспарентность ценообразования. Остается надеяться, что определенная непоследовательность в установлении сферы действия всего Регламента № 1008/2008 и его положений о транспарентности ценообразования не станет препятствием для достижения важнейшей цели

${ }^{25}$ Ibidem. 
нового Регламента, упомянутой выше, а будет устранена по мере его ревизии уполномоченными институтами и органами Союза.

В целом представляется, что третий пакет либерализации не только позволил открыть авиатранспортному рынку ЕС новые горизонты в будущем, в чем заключалось главное достижение первых двух пакетов, но и заложить прочную основу для развития внутреннего воздушного рынка ЕС на качественно новом уровне, отвечающем требованиям современных общественных отношений.

\section{Библиографический список}

Баталов А.А. Проблемы современного международно-правового регулирования воздушных сообщений. Дисс. на соиск. уч. степ. к.ю.н., Москва, 2003 г.

Бордунов В.Д. Международное воздушное право. Учебное пособие. - М.: НОУ ВКШ «Авиабизнес»; изд-во «Научная книга». 2006.

Европейское право. Право Европейского Союза и правовое обеспечение защиты прав человека: учебник / рук. авт. кол. и отв. ред. Л.М. Энтин.- 2-е изд., пересмотр. и доп. - М.: Норма, 2008.

Малеев Ю.Н. Воздушное пространство: основные конфликтные позиции государств. // Пространство и время в мировой политике и международных отношениях: материалы 4 Конвента РАМИ. В 10 т. / под ред. А.Ю. Мельвиля; Рос. ассоциация междунар. исследований. - М.: МГИМО-Университет, 2007. Т. 5.

Международное право: учебник / отв. ред. Ю.М. Колосов, Э.С. Кривчикова - 2-е изд., перераб. и доп. - М.: Междунар. отношения, 2005 г.

Остроумов Н.Н. Договор перевозки в международном воздушном сообщении. - М.: Статут, 2009.

Толстопятенко Г. П. Европейское налоговое право. Сравнительноправовое исследование. М.: Издательство НОРМА, 2001.

Balfour J., EC Regulation 1008/2008 on common rules for the operation of air services in the EC - The third package revisited. // Beaumont Bulletin. January 2009. Р. 4. Официальный сайт международной юридической фирмы Clyde \& Со. Систем. требования: Adobe Acrobat Reader. URL: http://www.clydeco.com/attachments/published/3460/Beaumont\%20 Bulletin\%202009_pdf.log.pdf.

Diederiks-Verschoor I.H.Ph., Butler M.A., An Introduction to Air Law. Kluwer Law International. 2006. 
Mendes de Leon. P. Cabotage in Air Transport Regulation. Martinus Nijhoff Publishers. 1992.

Weber L., EEC transport liberalization and the Chicago Convention. // Annals of Air and Space Law. Vol. XVII-I. 1992.

\section{EU: Legal Regulation of Air Services (Summary)}

\section{Vrbaski Lazar*}

Liberalisation of the EU aviation market laid the foundation for the present-day legal regulation of air services in the EU. Regulation No. 1008/2008 consolidated provisions on EU air carrier licensing, their access to internal air routes of the European Union and fares for air services to increase the efficiency and consistency of applicable EU law, in an attempt to raise the EU internal aviation market to a qualitatively new level of development. With a view to better grasp the achievements of the EU in this field, this article studies the modernisation of air services regulation through the comparative analysis of the main rules of the new Regulation and earlier acts, practical and scientific issues arising in the course of their application on the regional and global levels.

Keywords: Regulation No. 1008/2008; licensing; access to internal air routes; public service carriage; fares.

\footnotetext{
*Vrbaski Lazar - post-graduate student of the Chair of European Law, MGIMO-University,
} MFA Russia.kafedra-ide@mgimo.ru. 